\title{
LAS EDITORIALES CARTONERAS EN AMÉRICA LATINA (2003-2019). UNA NANO-INTERVENCIÓN EN LA CONSTRUCCIÓN DE LA WORLD LITERATURE
}

THE CARDBOARD PUBLISHING HOUSES IN LATIN AMERICA (2003-2019). A NANO-INTERVENTION IN THE MAKING OF WORLD LITERATURE

\section{Analía Gerbaudo}

ORCID 0000-0001-9969-8004

Universidad Nacional del Litoral

Santa Fe, Argentina

\section{Resumen}

El artículo examina un fenómeno que irrumpe en un campo literario situado en un espacio nacional periférico y se expande luego a América Latina, a América del Norte, Europa, Asia y África: las editoriales “cartoneras”. La singularidad de este movimiento está dada por la creación de un nuevo objeto, el "libro cartonero", que propone prácticas de producción y de circulación editorial alternativas a las hegemónicas. Su impacto no solo se verifica en los campos literario y editorial, sino también en el universitario y en el científico. En primer lugar, se caracteriza el proyecto de Eloisa cartonera, la primera editorial de este tipo creada en Argentina en 2003. En segundo lugar, se describen los efectos que esta editorial produce en los circuitos nacional, regional y transnacional. Dichos efectos dan cuenta de una intervención de orden "nano" en la llamada World Literature.

Palabras clave: Editoriales cartoneras, Argentina, literatura mundial, nanointervención.

\section{Abstract}

This article examines an event that emerged in a literary field situated in a peripheral national space and later expanded to Latin America, North America, Europe, Asia and Africa: the inception of the cartoneras or cardboard publishing houses. The singularity of this movement is due to the shaping of a new object: the "cartonero book". These cardboard publishing projects help dismantle the hegemonic circuits of both the production and the circulation of books. They have a great impact not only in the literary and the editorial fields but

\section{Resumo}

$\mathrm{O}$ artigo analisa um fenômeno que aparece no campo literário localizado num espaço nacional periférico. Esse fenômeno se expande para América Latina, América do Norte, Europa, Ásia e África: as editoras "cartoneras". A singularidade desse movimento está dada pela criação de um novo objeto: o "livro cartonero", que propóe práticas de produção e publicação alternativas às hegemônicas. Seu impacto não é apenas verificado nos campos literário e editorial, mas também na universidade 
also in the academic and the scientific fields. This paper first characterises the Eloisa Cartonera project, the first cardboard publishing house created in Argentina en 2003. Secondly, the paper will describe the effects of this project in the national, regional and transnational circuits. Finally, we show why we can consider these effects as nanointerventions in the making of World Literature.

Keywords: Publishing houses, Argentina, World Literature, nanointervention. e nos campos científicos. Em primeiro lugar, nos descrevemos o projeto de Eloísa cartonera, criado na Argentina em 2003. Em segundo lugar, descrevem-se os efeitos desse projeto nos circuitos nacionais, regionais e transnacionais. Esses efeitos são responsáveis duma intervenção "nano" na chamada World Literature.

Palavras-chave: editoriais cartoneras, Argentina, World Literature, nanointervenção.

Este artículo examina un problema que se deriva de la "teoría de la diferenciación social según el prisma de la historia global" propuesta por Gisèle Sapiro en 2013. Sapiro interroga el carácter nacional de los campos tomando en consideración los "flujos globales" de circulación de textos. En su análisis llama la atención sobre la capacidad de los centros, de los polos dominantes del campo a escala transnacional, para apropiarse de las invenciones producidas en la periferia: esta apropiación contribuye tanto a la visibilización como a la consagración de dichas invenciones.

Este problema es analizado aquí a partir del estudio de un caso. Se trata de un fenómeno que irrumpe en un campo literario situado en un "espacio nacional periférico"1 y se expande luego a América Latina, América del Norte, Europa, Asia y África. Se trata de la irrupción de las editoriales "cartoneras": su singularidad está dada por la creación de un nuevo objeto, el "libro cartonero", que propone prácticas de producción y de circulación editorial alternativas a las "hegemónicas" (WILLIAMS, 1977). Su impacto no solo se verifica en los campos literario y editorial, sino también en el universitario y en el científico.

1 Esta expresión se extrae de los trabajos de Sapiro (2009) y de Anna Boschetti (2009): ambas la utilizan para dar cuenta de un espacio geográfico territorialmente circunscripto que no amalgaman con el menos delimitado de "campo". La misma estrategia se observa en el texto de Sapiro y de Jérôme Pacouret (2015) en el que cuidadosamente se distinguen las fronteras ambivalentes de los campos y las jurídicamente precisas de los Estados. Por razones metodológicas, de todos modos, en algunos trabajos, Sapiro habla de "campos nacionales" ( $c f$. SAPIRO, 2003). 
En primer lugar, caracterizo el proyecto de Eloisa cartonera, la primera editorial de este tipo creada en Argentina en 2003. En segundo lugar, describo los efectos que esta editorial produce en los circuitos nacional, regional y transnacional. Dichos efectos dan cuenta de una intervención de orden "nano"2 en la llamada World Literature.

\section{Washington Cucurto y Eloísa cartonera: desacralizaciones sacrílegas}

La primera editorial cartonera surge en Argentina en 2003: el escritor Washington Cucurto y los artistas plásticos Fernanda Laguna y Javier Barilaro fundan en Buenos Aires Eloísa cartonera. Se trata de un tipo de intervención colectiva enmarcada en lo que Andrea Giunta ha caracterizado como el arte argentino "poscrisis" (2009). Es decir, son respuestas tramitadas desde la creación artística a los resultados de las políticas económicas aplicadas por los gobiernos neoliberales durante el primer ciclo de la posdictadura ${ }^{3}$ : "El siglo XX terminó a fines de 2001" (p. 26), resalta Giunta. "Sobre las imágenes de las torres gemelas convertidas en polvo se sobreimprimieron las de las ciudades argentinas, modificadas por las multitudes que reclamaban ante el estallido del sistema político, del sistema bancario y del Estado" (p. 26). En la revuelta social del 19 y 20 de diciembre de 2001 se combinan varios factores: la desocupación, la caída del mercado interno y de los ingresos de los sectores populares, la usurpación por los bancos de los depósitos de los ahorristas de clase media. Fueron días agitados por la toma de calles, plazas, espacios públicos y privados (asaltos a supermercados, faenamiento popular de ganado, ataques a edificios de bancos) y el cambio de tres presidentes en menos de dos semanas.

2 El témino "nano-intervención" (RONELL, 2008; 2011) subraya la "escala minúscula" de la acción, en el orden de "la pequeńa tarea" más que de "lo espectacular" (RONELL, 2011, p. 289).

3 Con matices diferentes, algunos investigadores (ANTELO, 2016; SCHWARZBÖCK, 2016) ensayamos conceptos de "posdictadura" en función de contribuir al análisis tanto del presente como del pasado reciente de Argentina. En un primer momento llamamos "posdictadura" al período comprendido entre 1984 y 2003 ( $c f$. GERBAUDO, 2016). Pero luego, frente a ciertas decisiones tomadas por el gobierno que ocupa el Estado a partir de diciembre de 2015, distinguimos un primer ciclo de la posdictadura, entre 1984 y 2003, y un segundo ciclo de la posdictadura, entre 2015 y el presente: estas decisiones suponen retrocesos en derechos humanos, laborales, educación, salud, ciencia, tecnología, comunicación, relaciones internacionales, economía, seguridad, etc. (cf. TZEIMAN, 2017; BEIGEL; SORÁ, 2019). Vuelven a abrirse las heridas nunca del todo cicatrizadas dejadas tanto por el terrorismo de Estado como por acciones que, aún bajo el orden democrático habían continuado algunas de las políticas económicas, culturales y simbólicas de la dictadura. Por lo tanto, es imperioso cuidar el modo de nombrar: el término "posdictadura" pretende llamar la atención sobre un tiempo marcado por huellas de otros. Como José Rabasa cuando esgrime sus razones para hablar de "poscolonialismo", es necesario aclarar que el prefijo "pos" subraya "las continuidades y legados" (2009, p. 220) entre un momento y otro: no es, de ninguna manera, la simple referencia a lo que viene después (cf. GERBAUDO, 2018a). 
Eloisa cartonera responde a esta situación desde la imaginación artística. Su proyecto cultural incluye a un sector marginal de la población: los "cartoneros" que viven de la venta de cartón que recolectan de las calles de las ciudades. Su intervención, a contracorriente de las lógicas económica y estética hegemónicas en el campo editorial, opera en cuatro órdenes: incorpora a los cartoneros como agentes centrales de un espacio de producción de bienes culturales; defiende la lógica del trabajo cooperativo; transforma tanto el valor simbólico del cartón recogido en la vía pública (la basura deviene tapa de libro) como la representación convencional del objeto "libro"; y convierte a ciertos consumos culturales expandidos en los sectores populares en sello de identidad de una nueva modalidad de producción y de circulación editorial.

A los efectos de aclarar el alcance de esta intervención es necesario precisar, por un lado, qué características definen la singularidad de las prácticas editoriales de Eloisa cartonera y, por el otro, cómo la transferencia de "capitales simbólicos" (BOURDIEU, 1997) consolidados gracias a una "revolución simbólica" (BOURDIEU, 2013a) producida en el campo literario le confiere, en un primer momento, visibilidad y luego, legitimidad en el campo editorial. Desarrollo estos dos puntos a continuación:

1 - La desacralización del objeto "libro" provocada por la lógica editorial cartonera es inescindible de la desacralización del objeto "literatura" provocada por la escritura de Cucurto. La irrupción de la literatura de Cucurto generó en Argentina no solo reacciones inconciliables en la crítica sino un debate alrededor del concepto de literatura ( $c f$. Ludmer, Sarlo, Contreras) $)^{4}$. Se trató de un "acontecimiento" (DERRIDA, 2003a; 2003b) literario y cultural: una revolución simbólica. La ruptura con lo esperable en un libro de literatura comprende desde su diseño hasta su propuesta formal y de contenido. A saber:

a) Cucurto escribe desde un español atravesado por los registros populares: se trata de una apropiación de la "lengua" puesta a funcionar en un "más allá de"s lo que hasta la irrupción de su escritura se reconocía como "literatura".

4 En 2005 Beatriz Sarlo escribe “¿pornografía o fashion?” donde defiende criterios de valoración de los textos que permiten distinguir "etnografía" de "literatura": "Si ya no se puede hablar de buena o mala literatura, dejemos de hablar de literatura" (2005, p. 14). Sandra Contreras lee en el concepto de "literaturas postautónomas" de Josefina Ludmer $(2006 ; 2007 ; 2010)$ una respuesta a esta toma de posición radical (cf. CONTRERAS, 2018, p. 102). Dejo para otra oportunidad del análisis de las derivas de esta polémica en la crítica argentina y latinoamericana. Me limito, en esta ocasión, a trascribir algunos de los pasajes en los que se advierte la réplica de Ludmer. Se trata de un planteo que revisa el concepto de "literatura": "Mi sistema literario no implica jerarquías ni valoraciones. No tiene entro ni periferia ni arriba ni abajo" (LUDMER, 2010, p. 89).

5 Empleo la expresión "más allá de" como la utiliza asiduamente Jacques Derrida en sus escritos, es decir, para dar cuenta tanto del cruce de un límite como del imperativo de 
b) Sus relatos cuestionan figuraciones heroicas de diferente orden que van desde los próceres idealizados por la transmisión escolar y los líderes políticos hasta los escritores. En sintonía con las búsquedas de profesionalización del escritor (cf. SAPIRO; RABOT, 2017), Cucurto toma distancia de su representación filantrópica. Como aprendimos de Bourdieu (1992), también hay un interés en la autofiguración que insiste en el desinterés.

c) Sus textos alteran el sistema de referencias y de citas. Por ejemplo, "Noches vacías", el primer relato incluido en el libro Cosa de negros (2003), envía a una cumbia compuesta e interpretada por la cantante popular Gilda. Por un lado, su operación repite el gesto de Judith Butler cuando se apropia del peyorativo término queer (BUTLER, 1993) o el de Ernesto Laclau cuando se apropia del despectivo término "populismo" (LACLAU, 2005): Cucurto elige como título de su libro una expresión insultante usada para caracterizar los supuestos habitus (BOURDIEU, 1972) de un grupo social al que pertenece. Como Butler y como Laclau, contribuye a transformar las condenas sociales en bandera política, en consigna identitaria y activista. Por otro lado, lejos de las profusas citas en francés y/o en inglés introducidas por los escritores del siglo XIX al XXI (pensemos en los epígrafes en Facundo de Domingo Faustino Sarmiento, en Rayuela de Julio Cortázar y en Los peligros de fumar en la cama y Las cosas que perdimos en el fuego de Mariana Enríquez, por ejemplo), las referencias de Cucurto pueden compararse, por su orden sacrílego, con las de Manuel Puig entre los años sesenta y setenta ( $c f$. BOLLIG, 2003): la inclusión literaria de los boleros y el cine de Hollywood es comparable con la inclusión literaria de la cumbia y su universo en Cucurto. Ambos profanan la literatura de su tiempo: ambos infringen las "leyes del género" (DERRIDA, 1980). Sus intervenciones "monstruosas" (DERRIDA, 1990a) desestabilizan la definición de literatura dominante en cada corte temporal.

d) A través de la autofiguración, Cucurto exhibe su poco convencional trayectoria como escritor: Santiago Vega, más conocido por su seudónimo Washington Cucurto, construye un personaje que resalta el pasaje de trabajador de un supermercado a escritor reconocido. Sus relatos dan cuenta de capitales sociales y culturales diferentes respecto de los detentados por los escritores consagrados del campo literario (se trata de capitales que, correlativamente, contribuirán a redefinir qué se entiende por "capital específico" de un escritor,

no dejarse detener por una frontera cuando algo lo justifique. Un doble movimiento que no pretende borrar o anular la demarcación sino más bien interrogarla. 
al menos, tal como se lo concibe desde el campo literario recortado dentro del espacio argentino). Cucurto se representa como "sapo de otro pozo": un extranjero, alguien que viene d'ailleurs (DERRIDA; FATHY, 2000), que se encuentra con la literatura por esos derroteros del "azar convertido en don" (SAER 1985, p. 117). A a los veinticinco años Santiago Vega no había terminado aún el colegio secundario y trabajaba como repositor de verduras en un supermercado de la cadena Carrefour. Era su primer trabajo formal. Allí conoce a Maxi, un estudiante universitario con el que comparte los almuerzos. Maxi le contagia el entusiasmo por los libros y lo invita a un recital de poesía. Corría el año 1998. Veinte años después, Cucurto recuerda así aquella escena ${ }^{6}$ :

No sabía qué hacer, si entrar o no. No veía a Maxi por ningún lado. Yo era un sapo de otro pozo. De pronto escuché a lo lejos leer al poeta. Yo estaba demasiado atrás. Ni veía el escenario. Solo escuchaba las palabras encadenadas: amor, pájaro, cielo, besos. Cosas simples que yo nunca había oído decir así. Cuando me fui, en la puerta, había una mesa de libros para la venta. Agarré uno y miré la foto en la contratapa. Era el poeta que había leído esa noche. Y ahí estaba el tipo en la foto, fumando, largando el humo como cualquiera. Parecía un hombre común, uno que me podía cruzar en la calle. Compré el libro de poemas. Llegué a mi casa y empecé a leer. Tenía la voz del tipo en mi cabeza. No pude parar. Leí de corrido, hasta el final. Al otro día llegué al supermercado y ahí nomás, del otro lado de los papeles que me daban para controlar las cantidades de cajas de verduras y de frutas que entraban a la verdulería, en la parte blanca de atrás, empecé a escribir una oda a la zanahoria, una oda a la lechuga. Odas que inventaba usando las palabras que le había oído recitar al poeta. (2018).

El poeta en cuestión era Juan Gelman.

e) La literatura de Cucurto "solicita"7 los conceptos de "valor literario" y de "gusto" al hacer de los consumos culturales de las clases populares su clave estética. Cucurto construye un universo literario que exhibe los estereotipos alrededor de la cumbia, el peronismo, los negros, la inmigración del Sur del continente instalada en Argentina. Pertenece a otra clase que llega a la consagración literaria: si David Vińas viviera, probablemente escribiría otro

6 Analizo estas autofiguraciones en término de "cuentos" (envío a otros trabajos donde preciso este concepto ya que, por razones de desarrollo, no puedo hacerlo aquí [cf. GERBAUDO, 2017; 2018b]).

7 Uso el término "solicitar" en el sentido derrideano de cuestionar, poner en duda, hacer oscilar los fundamentos. 
capítulo de Literatura argentina y realidad politica ${ }^{8}$ a propósito de Cucurto. Esta otra clase inventa otra literatura: se trata de una revolución simbólica que va desde la escritura hasta el diseño. Se trata de una literatura que sacraliza lo abyecto y profana lo inmaculado: diseñar las tapas de un libro a partir de los carteles de colores chillones que anuncian recitales de cumbia, armar sus interiores con papeles llamativos que promocionan ofertas de supermercados, escribir una "oda" a Cristina Kirchner (cf. CUCURTO, 2010), fotografiarse en la tapa de los libros confundiéndose con sus personajes (siempre negros: un negro curandero, un negro héroe de la independencia, un negro trabajador de supermercado), son solo algunas de las desacralizaciones que Santiago Vega practica mientras produce una literatura que, además, como un "bucle extraño" (HOFSTADTER, 1979), vuelve reflexivamente sobre estas operaciones. Dicho en otros términos: estas operaciones "monstruosas" hacen de la literatura de Cucurto un "acontecimiento". Esto consolida su nombre como una "firma" (DERRIDA, 1990b) del campo literario. Esta posición contribuye a visibilizar las singulares prácticas editoriales que impulsa desde Eloísa cartonera: allí produce otra revolución simbólica. Eloisa cartonera altera lo que hasta entonces se reconocía como libro y los circuitos de producción y circulación editoriales.

2 - Eloisa cartonera desarrolla un proyecto que marcha a contracorriente de las lógicas editoriales del circuito de "gran producción", regido por criterios de mercado. Su innovación se tramita desde una nueva forma de plantear la producción y circulación en "pequeña escala” (BOURDIEU, 1977). A saber:

a) Cada libro es un objeto único producido de modo artesanal: las tapas, pintadas a mano con témperas de colores llamativos, se hacen con el cartón provisto por los cartoneros.

b) Las tiradas iniciales van de 400 a 1500 libros, según se trate de un texto de un escritor reconocido o de un escritor en sus inicios.

c) Los escritores ceden su texto de modo gratuito a la cooperativa Eloísa cartonera.

8 Durante toda su vida, Viñas ha reescrito un mismo libro: Literatura argentina y realidad politica (Cf. VIÑAS, 1964; 1970; 1995; 1996). En sus diferentes versiones (cada una con distintos epígrafes en los que se suceden Robert Escarpit, Mao y Terry Eagleton) insiste sobre una misma tesis: la literatura argentina es "la historia de los sucesivos intentos de una comunidad por convertirse en nación" (1964, p. 14). Esa historia exige "una lectura política": se trata, según Viñas, de "un texto único donde la burguesía habla" (1971, p. 10). Con implícita referencia a Lucien Goldmann y a su metodología (cf. GOLDMANN, 1955), Viñas subraya cómo los textos traducen las "visiones de mundo" del grupo social al que pertenecen sus autores. 
d) El catálogo se define a partir de la valoración de los textos con independencia de su "éxito" comercial. Actualmente ronda los 200 títulos. Se privilegia la publicación de autores latinoamericanos. En la selección hay firmas consagradas junto a escritores no conocidos. Por ejemplo, junto a Gabriela Bejerman, Fabián Casas, Damián Ríos, Néstor Perlongher, Ricardo Piglia, Haroldo de Campos, Raúl Zurita, César Aira, Pedro Lemebel, Juan Incardona, Martín Gambarotta, Enrique Lihn, Víctor Gaviria, Glauco Matosso, Elder Silva, Gonzalo Millán, Carmen Ollé, Ricardo Zelarayán, etc., se publican los textos premiados en los concursos organizados por la cooperativa. El nombre del premio que desde 2013 entrega la editorial, Sudaca border, repite el gesto cucurtiano de convertir una expresión despectiva en sello de identidad: se combina una forma ofensiva usada especialmente en España para nombrar al inmigrante latinoamericano con un polisémico término en inglés. Transformar el insulto o lo que avergüenza en una marca sostenida con orgullo es la operación política más importante de Eloísa cartonera. Esta operación se repite en la justificación del catálogo: se trata de una selección realizada por un grupo que exhibe los capitales que acumula a contrapelo de sus herencias culturales. Se trata de marcas de "agencia" (SAPIRO; STEINMETZ; DUCOURNAU, 2010). En la página Web de Eloísa cartonera se lee: "Nuestros libros son de literatura latinoamericana, de los autores más bellos que hemos conocido en nuestras vidas de trabajadores y lectores" (COLECTIVO ELOÍSA CARTONERA, 2018).

e) El catálogo por venir promete exhumaciones que cooperan en los trabajos de memoria. Por ejemplo, en la página Web de Eloísa cartonera se lee: "Nuestro sueño es editar los cuentos completos de Rodolfo Walsh, un escritor argentino, un intelectual del pueblo, un periodista formidable que mataron los militares en 1976" (COLECTIVO ELOÍSA CARTONERA, 2018) ${ }^{9}$. Luego de esta aclaración se traen los nombres de otros escritores, víctimas de la última dictadura: Paco Urondo, Haroldo Conti. Y se subraya: “¿Cartón es vida y vuelven todos en el cartón! Si Rodolfo Walsh viviera, le encantaría la idea" (COLECTIVO ELOÍSA CARTONERA, 2018).

9 La noción de "pueblo" es una construcción: aún cuando se parta de perspectivas no convergentes ( $c f$. BUTLER, 2013; BOURDIEU, 2013b; LACLAU, 2005; MOUFFE, 2017; AGUILAR, 2015), se coincide en señalar la distancia entre la población en base a la cual se proyectan diferentes representaciones del "pueblo". Se trata de un constructo sujeto a las tensiones que atraviesan los espacios sociales particulares y los cambiantes tiempos históricos. Por ejemplo, según las circunstancias se intentará construir al "pueblo" en oposición a la "oligarquía", a las multinacionales, a los inmigrantes, al capitalismo, al neoliberalismo, a la "casta", etc. Cabe aclarar que en la misma coyuntura convive más de una construcción respecto de lo que el pueblo "sería", representaría o encarnaría. Esta diseminación del término también se observa en los textos que sube a la Web el colectivo Eloisa cartonera. 
f) La estética de los lugares de producción y venta de los libros refuerza el gesto inclusivo respecto de los consumos culturales de ciertos sectores sociales populares. Por ejemplo, los vidrios y las paredes externas de la cooperativa Eloisa cartonera están pintados con colores chillones mientras que la producción de libros es acompañada con la cumbia como música de fondo.

g) La circulación de los libros es impulsada por una mediación didáctica que promueve el trabajo cooperativo y la conciencia ecológica, además del envío a la literatura a través de las "clases" informales que Cucurto dicta cuando vende libros en ferias y congresos. Se trata de una forma de difusión no circunscripta a la ciudad de Buenos Aires:

Nosotros somos una editorial de difusión (...) Siempre vamos a todas las ferias. Vamos a todos lados: llegamos a un pueblito de La Rioja, donde no va nadie, y ponemos nuestros libritos en las mesas y en una hora se venden todos. Y también recomendamos mucho, porque la gente no nos conoce. No todo el mundo conoce a Piglia. No todo el mundo conoce a un montón de autores. Y nosotros recomendamos (...). Entonces la gente compra. (...) Y el libro es también una buena noticia. Eso es algo que me dijeron en Chile. Siempre me acuerdo de eso porque era la época de la crisis (...). Nosotros fuimos con los libros a un festival de poesía. Y la gente compraba los libros y decía 'al fin una buena noticia de Argentina'. (2009, p. 74)

En un tiempo out of joint (DERRIDA, 1993) transido por la "ruptura" del "lazo social" (DUFOURMANTELLE, 2014) y por la despreocupación irresponsable respecto del medioambiente y de la soberanía alimentaria, Eloisa cartonera promueve la lógica del cooperativismo y la toma de conciencia ecológica. Gracias a la compra de una hectárea de tierra en Florencio Varela (una localidad del Gran Buenos Aires) y al asesoramiento de investigadores del Instituto Nacional de Tecnología Agropecuaria (INTA), el grupo armó una huerta orgánica. En la Web de Eloisa cartonera, en el apartado "Agricultura popular sostenida por la comunidad", se lee: "Podrán venir los niños a aprender la importancia de la agricultura popular, por ejemplo. En Eloisa creemos que es fundamental que las nuevas generaciones tomen conciencia del valor de la vida y de la tierra" (COLECTIVO ELOÍSA CARTONERA, 2018).

h) Con distancia crítica respecto de lo que se hace desde el Estado, este colectivo alerta tanto contra la romantización de la pobreza como contra su estetización: el cartón es una marca de identidad y a la vez una metáfora de una manera de intervenir que no niega la condición por-venir de otras. Por ejemplo, la traducción de la página Web de Eloisa cartonera al inglés dada la 
importancia de la venta de los libros en euros o dólares es congruente con la posición de Cucurto respecto de la profesionalización del escritor.

De los campos literario y editorial a los campos universitario y científico

En 2012 se crea en la Universidad Nacional de Córdoba La Sofía cartonera (cf. PACELLA, 2017) y, algunos años más tarde, en la Universidad Nacional de Rosario, Rita cartonera (cf. BERNABÉ, 2017). El catálogo de ambas se centra en literatura. En 2016 empieza a funcionar Vera cartonera en un espacio institucional compartido entre la Universidad Nacional del Litoral y el Consejo Nacional de Investigaciones Científicas y Técnicas (CONICET). Las tres editoriales son dirigidas por mujeres y, como la mayoría de las editoriales cartoneras, tienen nombre de mujer.

Lo distintivo de Vera cartonera es su institucionalización de doble pertenencia en una universidad pública y en el organismo de investigación más prestigioso del país fundado en 1958. Esto tiene sus consecuencias en diferentes planos de acción. En principio, en la propuesta editorial: el catálogo incluye literatura junto a divulgación científica y cultural en campos que van desde las ciencias biológicas hasta las ciencias humanas y sociales. Se trabaja con recetas de cocina, literatura para niños y jóvenes, poesía, teatro, narrativa, traducciones, crónicas, divulgación científica, notas de prensa. Hay colecciones que tratan problemáticas determinadas como cuestiones de género, trabajos de memoria, reflexiones sobre la lengua, la enseñanza, críticas de cine. Cuando se trata de géneros literarios, el catálogo prioriza la publicación de escritores del circuito independiente dado que tienen menos posibilidades de hacer conocer su obra que quienes publican en los grandes grupos editoriales. $\mathrm{Si}$ bien se imprimen tiradas iniciales de 50 a 400 ejemplares, se planifica una difusión vía la Web y se reimprimen los títulos agotados. El equipo que trabaja en Vera cartonera está formado por escritores, científicos, traductores, profesores, diseñadores, periodistas, estudiantes y realizadores audiovisuales.

Las colecciones están dirigidas a un público con capitales culturales divergentes. El objetivo fundamental de la editorial es crear nuevos lectores: la principal batalla se libra contra el "eso no es para nosotros" (BOURDIEU, 1979). Es decir, se lucha contra la autoexclusión del circuito de consumo de ciertos bienes culturales por quienes no los tuvieron como herencia familiar. Para ello se instalan puestos de venta en ferias y festivales celebrados en la ciudad y en la región. También se realizan talleres de armado de libros y talleres de lectura en escuelas. Es decir, no se deja al texto librado a su suerte en una librería ni en una biblioteca. Por el contrario, el libro es acercado al lector desde una mediación que no solo lo involucra intelectual y emocionalmente, sino 
que lo incluye en el proceso de producción. "Llevé a un profesor extranjero a la cartonera de Cucurto", afirma Gustavo Bombini, profesor de la Universidad de Buenos Aires y de la Universidad Nacional de San Martín. Y sigue: "mi colega no lo podía creer. Hacían el libro para él, lo armaban y lo pintaban y se lo entregaban" (BOMBINI, 2019). Ese efecto se profundiza en los talleres de producción de Vera cartonera ya que los potenciales lectores arman su propio libro.

Otra marca de los libros es su carácter breve: esto obedece no solo a que sus características materiales exigen esa extensión. Se trata, también, de una tensión entre lo pensable y lo posible, tanto en términos de producción como de circulación y consumo: se intenta contribuir a generar nuevos lectores porque se apuesta a la lectura como una de las vías privilegiadas en la construcción de agencia política (GARCÍA CANCLINI, 2018). Se intenta, entonces, acercar un bien simbólico de calidad a bajo precio. La sesión de derechos por los escritores abarata el precio final que, en el caso de las escuelas y los talleres públicos, se reduce a $0 \$$ dado que los ejemplares producidos se regalan, ya sea a la biblioteca de la institución (en el caso de las escuelas), ya sea a quienes han armado su propio libro (en el caso de las ferias).

El sistema de ventas intenta favorecer el consumo de los textos del catálogo: si comprar un libro de Vera cartonera en un pasillo de la facultad o en una feria cuesta $60 \$$ (es decir, 1 dólar con algunos centavos), comprar dos títulos costará $100 \$$ y tres, $120 \$$ (es decir, menos de un dólar por libro). Se busca estimular la adquisición del libro a partir de una oferta tentadora en términos económicos. El libro es un objeto suntuoso incluso para un amplio sector de la clase media baja argentina y de nuestro estudiantado universitario, aun cuando la carrera elegida haya sido letras (recordemos que las carreras de grado universitario en Argentina son gratuitas: a ellas acceden estudiantes de ingresos económicos diversos).

Finalmente, el proyecto defiende la intervención continua en pocos lugares. Se trata de una posición ética: por un lado, se busca asegurar la continuidad de prácticas en un país marcado por la discontinuidad de sus políticas públicas. Por el otro, se busca evitar la megalomanía redentora. Como observa Alejandro Miranda, integrante del grupo de Eloisa cartonera: "¿Tiene sentido ir una tarde a mostrarle a un chico cómo hacer un libro si nadie va a sostener esa iniciativa a través del tiempo? (...) En las villas, hay que enseñar trabajo sostenible. $\mathrm{Y}$ a los chicos, hay que darles primero agua, cloacas, luz. Después de eso, podemos pensar en los libritos" (MIRANDA, 2018). Por razones de este orden, el equipo de Vera cartonera, centra su trabajo en escuelas: se interviene en instituciones que garantizan la cobertura de algunos derechos básicos, además de educación. 
En Latinoamérica, el proyecto de Eloisa cartonera se disemina en Brasil, Colombia, México, El Salvador, Paraguay, Ecuador, Uruguay, Panamá, Chile, Costa Rica, Puerto Rico, Venezuela, Perú, Guatemala, Cuba, República Dominicana y Bolivia. Menciono solo algunas de estas editoriales cartoneras. Por ejemplo, en Chile, un país donde el libro y la educación universitaria tienen un alto costo económico, Animita Cartonera enfatiza las "propuestas de contenido" de sus libros. En Brasil, Dulcinéia Catadora resalta el hecho de publicar "autores nuevos que abren espacio para un camino paralelo al mercado editorial": el grupo piensa sus intervenciones en términos de "resistencia y crítica a las prácticas tradicionales". En México, La Cartonera destaca la internacionalización de sus productos: la página muestra, por ejemplo, más de tres librerías de París donde se venden sus libros e incluye un video, How to make a cartonera book / Cómo hacer un libro cartonero, subvencionado por el programa de investigación Cartonera publishing de la Universidad de Surrey. En Bolivia, Yerba mala cartonera no sólo pone a disposición en la Web su catálogo sino también sus textos para su lectura on line junto a videos grabados por sus autores.

Esta lógica de producción, circulación y gestión editorial se reprodujo en Estados Unidos, Mozambique, China y proliferó en Europa (hay editoriales cartoneras en España, Suecia, Portugal, Italia, Alemania, Finlandia y Francia). Las bases de datos disponibles dan cuenta de más de 290 editoriales de este tipo en el mundo. Sólo menciono, a los efectos de no exceder el espacio pautado por esta revista para sus artículos, algunos de los proyectos registrados en Francia dada la centralidad de este país en la "república mundial de las letras" (CASANOVA, 1999). Empecemos por Cephisa cartonera: esta editorial, creada en 2011 en Clermont-Ferrand, abre su página Web con un envío a un video filmado junto al grupo de Eloisa cartonera en Buenos Aires. Es decir, se trata de un grupo francés que define su identidad a partir del proyecto argentino. Ambos equipos trabajan en colaboración y publican co-ediciones bilingües francés/español. Por ejemplo, han publicado en coedición y presentado en Argentina Le premier Noël du père Noël de Emilie Giraudet con ilustraciones de Florencia Rodríguez.

Como el caso anterior, Ivonne cartonera define su identidad a partir de Eloisa cartonera: en el inicio de su página Web el grupo resalta que Eloísa... nace en Buenos Aires como respuesta al estallido social de 2001. Por su parte, frente a la producción industrial de libros, Yvonne cartonera apuesta a la escala reducida, artesanal y a los talleres de producción y lectura en París.

Como en los dos casos anteriores, La guêpe cartonnière define su identidad a partir de Eloísa cartonera. Su catálogo privilegia la traducción 
al francés de autores latinoamericanos así como la publicación de jóvenes escritores franceses. Se destacan la edición bilingüe francés/español del libro de poemas Consumidor final de Pedro Mairal así como la traducción al francés de poesía (Le saumon de Fabián Casas, Zelarayán de Cucurto, entre otros) y de narrativa (Niño Rico de Dani Umpi, Panamá de Cucurto, entre otros). Por otro lado, el equipo francés ha impulsado la primera editorial cartonera en China: en 2010 contribuyeron a fundar Mil hojas cartonera en Pekín.

Como se puede corroborar en los sitios Web de estas editoriales y como se desprende de esta brevísima descripción, se trata de proyectos que se apropian de la iniciativa de Eloisa cartonera generando diferentes derivas. Por otro lado, el proyecto de Eloisa cartonera ha sido analizado en diferentes lugares del mundo ( $c f$. BILBIJA; CARBAJAL, 2009; CANO REYES, 2011; HEFFES, 2014; BOLLIG, 2016; BILBIJA, 2017). A su visibilidad contribuyen los estudios críticos, congresos y talleres de producción de libros cartoneros generados desde prestigiosos centros asociados a la consagración intelectual y/o artística internacional como la Universidad de Oxford, el Museo Reina Sofía, la Universidad de Wisconsin, etc.

Como resalta la escritora mexicana Ingrid Bringas en un video subido a la Web por Yerba mala cartonera, se observa un fenómeno de diseminación internacional de los catálogos de estas pequeñas editoriales. A esa diseminación contribuyen las traducciones. Por ejemplo, Cardboard house. Cartonera Collective, radicada en Estados Unidos, traduce al inglés autores latinoamericanos con diferentes trayectorias. Por ejemplo, se traduce a escritores consagrados como la chilena Carmen Berenguer o el argentino Néstor Perlonguer junto a la joven poeta argentina Daiana Henderson que, radicada en el interior del país, construyó su prestigio en los festivales de poesía y en las editoriales independientes. Este último dato subraya la importancia de las nuevas tecnologías para difundir tanto los proyectos editoriales de producción restringida como los festivales de literatura organizados en diferentes ciudades (no necesariamente las grandes capitales): la cartografía de la "república mundial de las letras" (CASANOVA, 1999) se altera por la acción de agentes que, desde estas "formaciones" (WILLIAMS, 1977), producen y ponen en circulación bienes simbólicos desde lógicas alternativas respecto de las "hegemónicas" (WILLIAMS, 1977).

Es imperioso subrayar que no se trata solamente de una intervención en los campos literario y editorial, sino también teórico: estas nuevas prácticas obligan a replantear algunas de las categorías existentes hasta su emergencia. Por ejemplo, la dicotomía entre bienes culturales de ciclo corto y de esperada ganancia inmediata y bienes culturales de ciclo largo, indisociables del riesgo que supone lanzar al mercado un objeto cultural no estandarizado según los gustos masivos, se desdibuja desde esta lógica editorial que, además, en un 
momento de crisis económica generalizada, ofrece productos de alta calidad artística a bajo precio. Se trata, además, de un movimiento con flujo SurNorte. Es decir, un movimiento que marcha a contrapelo, junto a algunos otros, de las circulaciones teóricas hegemónicas ( $c f$. MIRIZIO et al., 2016).

Para concluir: las editoriales cartoneras generan nuevos modos de producción y de circulación de la literatura y del conocimiento en general. Puntualmente Eloísa cartonera suscita además un movimiento de flujos fuera de cálculo: se trata de un "acontecimiento" que impulsa no sólo prácticas editoriales similares en diferentes lugares del mundo, sino una insospechada diseminación internacional de una literatura escrita en una periferia, en una lengua marginal en la circulación internacional de los bienes simbólicos y publicada desde un polo editorial de producción restringido. Este singular movimiento Sur-Norte marcha a contracorriente respecto de las tendencias hegemónicas y promueve nuevas formas de consagración literaria comparables, al "proceso democratizador" impulsado por los festivales ( $c f$. SAPIRO, 2016) ${ }^{10}$. Se trata de una "revolución simbólica". O dicho en términos de Derrida, de una "anomalía" "monstruosa". Se trata, también, de una intervención de orden "nano" en la llamada World Literature (DAMROSCH, 2003).

\section{Referencias}

AGUILAR, Gonzalo. Más allá del pueblo. Imágenes, indicios y politicas del cine. Buenos Aires: FCE, 2015.

ANIMITA CARTONERA. <https://animitacartonera.wordpress.com>. Fecha de captura: 20.12.2018.

ANTELO, Raúl. Programa para un posgrado futuro. El taco en la brea, n. 3, 144171, 2016.

BEIGEL, Fernanda; SORÁ, Gustavo. Arduous Institutionalization in Argentina’s SSH: Expansion, Asymmetries and Segmented Circuits of Recognition. Shaping Human Science Disciplines. Socio-Historical Studies of the Social and Human Sciences. London: Palgrave Macmillan, 2019, p. 327-360.

10 Tal como hizo Sapiro en Francia con los festivales, actualmente estamos examinando, a través de encuestas y entrevistas, qué sectores sociales de Argentina consumen los productos de las editoriales cartoneras. Dicho en otros términos: quiénes leen los libros que publican, a qué sectores sociales llegan estas prácticas. 
BERNABÉ, Mónica. Literatura y prácticas editoriales alternativas. XIII Argentino de literatura. Santa Fe: UNL, 2017

BILBIJA, Ksenija. Semblanza de Sarita cartonera (2004-2011). Biblioteca Virtual Miguel de Cervantes. Alicante: Biblioteca Virtual Miguel de Cervantes, 2017.

BILBIJA, Ksenija y Paloma Celis Carbajal. Akademia cartonera: A Premier of Latin American Cartonera Publishers. Wisconsin: University of Wisconsin, 2009.

BOLLIG, Ben. Manuel Puig: The Exploitation and Subversion of Stereotypes. Bulletin of Hispanic Studies, v. 80, n.2, p. 247-256, 2003.

BOLLIG, Ben. Politics and Public Space in Contemporary Argentine Poetry : the Lyric and the State. New York: Palgrave Macmilan, 2016.

BOMBINI, Gustavo. Consulta por Analía Gerbaudo. CONICET /CAI+D UNL, 2019.

BOSCHETTI, Anna. La recomposition de l'espace intellectuel en Europe après 1945. L'espace intellectuel en Europe. De la formation des États-nations à la mondialisation (XIX'-XXI siècle). Paris : La Découverte, 2009, p. 147-182.

BOURDIEU, Pierre. Esquisse d'une Théorie de la Pratique précédé de Trois Études d'ethnologie kabyle. Genève: Droz, 1972.

BOURDIEU, Pierre. La production de la croyance [contribution a une économie des biens symboliques]. Actes de la Recherche en Sciences Sociales, n. 13, p. 3-43, 1977.

BOURDIEU, Pierre. La distinction. Critique sociale du jugement. Paris: Minuit, 1979.

BOURDIEU, Pierre. Las règles de l'art. Genèse et structure du champ littéraire. Paris: Seuil, 1992.

BOURDIEU, Pierre. Une révolution conservatrice dans l'édition. Actes de la Recherche en Sciences Sociales, n. 126-127, p. 3-28, 1999.

BOURDIEU, Pierre. Méditations pascaliennes. Paris: Seuil, 1997.

BOURDIEU, Pierre. Manet. Une révolution symbolique. Cours au Collège de France (1998-2000) suivis d'un manuscrit inachevé de Pierre et Marie-Claire Bourdieu. Edición establecida por Pascale Casanova, Patrick Champagne, Christophe Charle, Frank Poupeau et Marie-Christine Rivière. Paris: Raisons d'Agir/Seuil, 2013a.

BOURDIEU, Pierre.Vous-avez dit 'populaire'. In: Qu'est-ce qu'un peuple ? Paris: La fabrique. $2013 \mathrm{~b}$.

BUTLER, Judith. Cuerpos que importan. Sobre los limites materiales y discursivos del 'sexo'. Trad. Alcira Bixio. Buenos Aires: Paidós, 2002. 
BUTLER, Judith. 'Nous le peuple' : réflexions sur la liberté de réunion. In : Qu'est-ce qu'un peuple? Paris: La fabrique. 2013, p. 53-76.

CANO REYES, Jesús. ¿Un nuevo boom latinoamericano? La explosión de las editoriales cartoneras. Espéculo , n. 47, 2011. Disponible en: https://webs.ucm.es/info/ especulo/numero47/boomlati.html

CARDBOARD House. Cartonera Collective. https://www.facebook.com/ TheCardboardHousePress/. Fecha de captura: 20.12.2018.

CASANOVA, Pascale. La république mondiale des lettres. Paris : Du Seuil, 1999.

CEPHISA Cartonera. < http://cephisakartonera.wordpress.com>. Fecha de captura: 20.12.2018.

COLECTIVO Eloísa cartonera. Mucho más que libros. http://www.eloisacartonera. com.ar/historia.html. Fecha de captura: 20.12.2018. 2018

CONTRERAS, Sandra. En torno al realismo y otros ensayos. Rosario: Nube Negra, 2018.

CUCURTO, Washington. 1810. La Revolución de Mayo vivida por los negros. Buenos Aires: Emecé, 2003

CUCURTO, Washington. El catálogo: construir la propuesta editorial. V Argentino de literatura. Santa Fe: UNL/CEDINTEL, 2009.

CUCURTO, Washington. Hombre de Cristina. Córdoba: La Sofía cartonera, 2010.

CUCURTO, Washington. La editorial cumple 15 años. Anfibia. Disponible en: $<$ http://revistaanfibia.com/cronica/la-osa-poderosa-eloisa-cartonera>. 2018

DAMROSCH, David. What is World Literature? Princeton: Princeton UniversityPress, 2003.

DERRIDA, Jacques. La loi du genre. In : Parages (Nouvelle édition revue et augmentée). Paris: Galilée, 2003 [1980], p. 233-266.

DERRIDA, Jacques. Passages -du traumatisme à la promesse. In : Points de suspension. Entretiens, Paris, Galilée, 1992 [1990a].

DERRIDA, Jacques. Postface: Vers une éthique de la discussion. In : Limited Inc., a b c... Paris: Galilée, 1990b, p. 199-285.

DERRIDA, Jacques. Spectres de Marx. L'État de la dette, le travail du deuil et la nouvelle Internationale. Paris: Galilée, 1993.

DERRIDA, Jacques. Genèses, généalogies, genres et le génie. Les secrets de l'archive. Paris: Galilée, 2003a. 
DERRIDA, Jacques. Auto-immunités, suicides réels et symboliques. Un dialogue avec Jacques Derrida ;La déconstruction du concept du terrorisme selon Derrida. Le "concept» du 11 septembre. Dialogues à New York (octobre décembre 2001). Paris: Galilée, 2003b, p. 133-244.

DERRIDA, Jacques; FATHY, Safaa. Contre-jour. Tourner les mots. Au bord d'un flm. Paris: Galilée, 2000, p. 11-25.

DUFOURMANTELLE, Anne. Pour qui, pour quoi risquer ou donner sa vie aujourd'hui? La Grande Table. France Culture. Emisión del 2 de junio. 2014.

DULCINÉIA CATADORA. <http://www.dulcineiacatadora.com.br/> Fecha de captura: 20.12.2018.

FATHY, Safaa. D’ailleurs, Derrida. Gloria Films Production / La Sept Arte, 1999.

GARCÍA CANCLINI, Néstor. La universidad vista desde las culturas de los jóvenes. VII Encuentro Nacional y V Latinoamericano sobre la universidad como objeto de investigación. Santa Fe: UNL, 2018.

GERBAUDO, Analía. Politicas de exhumación. Las clases de los criticos en la universidad argentina de la posdictadura (1984-1986). Los Polvorines/Santa Fe: UNGS/ UNL, 2106.

GERBAUDO, Analía. Derivas conceptuales (un borrador)”. IV Coloquio de avances de investigaciones del CEDINTEL. Santa Fe: UNL, 2017, p. 84-107. Disponible en: <https://www.fhuc.unl.edu.ar/cedintel/wp-content/uploads/sites/16/2019/07/ Coloquio-IV.pdf>. Fecha de captura: 20.12.2018.

GERBAUDO, Analía. Ante un segundo ciclo de la posdictadura. El taco en la brea, n. 6, p. 4-8. 2018a. Disponible en: <https://bibliotecavirtual.unl.edu.ar/ publicaciones/index.php/ElTacoenlaBrea/article/view/6960> Fecha de captura: 20.12.2018.

GERBAUDO, Analía. El fuego, el agua, la biodegradabilidad. Apuntes metodológicos para un archivo por-venir. In: ARÁN, Pampa y VIGNA, Diego (Dir.). Archivos, artes y medios digitales. Teoría y práctica. Córdoba: Centro de Estudios Avanzados-UNC, 2018b, p. 41-65. Disponible en: <https://rdu.unc.edu.ar/ handle/11086/6736? show=full $>$ Fecha de captura: 20.12.2018.

GIUNTA, Andrea. Poscrisis. Arte argentino después de 2001. Buenos Aires: Siglo XXI, 2009.

GOLDMANN, Lucien. Le Dieu caché. Étude sur la vision tragique dans les Pensées de Pascal et dans le théâtre de Racine. Paris : Gallimard, 1955.

HEFFES, Gisela. Del suburbio a la villa miseria: una lectura de los itinerarios (e imaginarios) urbanos a partir de Borges. Borges - Buenos Aires: configuraciones de 
la ciudad del siglo XIX al XXI. Madrid/Frankfurt: Iberoamericana/VervuertVerlag, 2014, p. 175-193.

HOFSTADTER, Douglas. Gödel, Escher, Bach. Un Eterno y Grácil Bucle. Barcelona: Tusquets, 1998. Traducción de Mario Usabiaga y Alejandro López Rousseau, 1979.

LA CARTONERA. <http://edicioneslacartonera.blogspot.com/> Fecha de captura: 20.12.2018.

LACLAU, Ernesto. La razón populista. Buenos Aires: FCE, 2009 [2005].

LA GUÊPE CARTONNIÈRE. <http://editionsdelaguepe.blogspot.fr/> Fecha de captura: 20.12.2018].

LUDMER, Josefina. Literaturas postautónomas. Disponible en: <http://www. loescrito.net>. 2006

LUDMER, Josefina. Panel Intervenciones en la crítica. III Congreso Argentino de literatura. Santa Fe: UNL, 2007.

LUDMER, Josefina. Aqui América Latina. Una especulación. Buenos Aires: Eterna cadencia, 2010.

MIRANDA, Alejandro. La editorial cumple 15 años. Anfibia. <http://revistaanfibia. com/cronica/la-osa-poderosa-eloisa-cartonera/>. 2018.

MIRIZIO, A., et al. La relación Sur-Norte en los estudios literarios en España (19662010): Argentina como un caso de inversión de las dinámicas internacionales en la circulación de los discursos de la teoría. Barcelona: Grupo Gliciart, 2016.

MOUFFE, Chantal. Le gauche et le peuple. France culture. Emisión del 28 de marzo. 2017.

PACELLA, Cecilia La Sofía cartonera. Una propuesta de edición y de extensión en la universidad pública. Nano-intervenciones con la literatura y otras formas del arte. Santa Fe: UNL, 2017.

RABASA, José. Poscolonialismo. Diccionario de Estudios Culturales Latinoamericanos. México: S. XXI-Instituto Mora, 2009, p. 219-223.

RONELL, Avital. Derridémocratie. Colloque International Derrida Politique. Paris: ENS, 2008.

RONELL, Avital. Entretien. La faute à Mallarmé. L'aventure de la théorie littéraire. Paris: Du Seuil, 2011, p. 290-296.

SAER, Juan José. Glosa. El entenado. Córdoba : Alción editora, 2008 [1985].

SAPIRO, Gisèle. (Dir.). L'espace intellectuel en Europe. De la formation des États-nations à la mondialisation (XIXe-XXIe siècle). Paris: La Découverte, 2009. 
SAPIRO, Gisèle. Le champ est-il national ? La théorie de la différentiation sociale au prisme de l'histoire globale. Actes de la Recherche en Sciences Sociales, n. 200, p. 70-85, 2013.

SAPIRO, Gisèle. The metamorphosis of modes of consecration in the literary field: Academies, literary prizes, festivals. Poetics, n .59, p. 5-19, 2016.

SAPIRO, Gisèle; STEINMETZ, George; DUCOURNAU, Claire. La production des représentations coloniales et postcoloniales. Actes de la recherche en sciences sociales, v. 185, n. 5, p. 4-11, 2010.

SAPIRO, Gisèle; PACOURET, Jérôme. La circulation des biens culturels : entre marchés, États et champs. Guide de l'enquête globale en sciences sociales. Paris : CNRS, 2015, p. 68-93.

SAPIRO, Gisèle; RABOT, Cécile. Profession? Écrivain. Paris: CNRS Éditions, 2017

SARLO, Beatriz. ¿Pornografía o fashion ? Punto de vista, n. 83, p. 13-17, 2005

SCHWARZBÖCK, Silvia. Los espantos. Estética y postdictadura. Buenos Aires: Cuarenta Ríos, 2016.

TZEIMAN, Andrés. Radiografía politica del macrismo. La derecha argentina: entre la nación excluyente y el desafío democrático. Buenos Aires: Caterva, 2017.

VIÑAS, David. Literatura argentina y realidad politica. Buenos Aires: CEAL, 1994 [1964].

VIÑAS, David. Literatura argentina y realidad politica. De Sarmiento a Cortázar. Buenos Aires: Siglo Veinte, 1971 [1970].

VIÑAS, David. Literatura argentina y política I. De los jacobinos porteños a la bohemia anarquista. Buenos Aires: Sudamericana, 1995.

VIÑAS, David. Literatura argentina y politica II. De Lugones a Walsh. Buenos Aires: Sudamericana, 1996.

WILLIAMS, Raymond. Marxism and literature. Oxford-New York: Oxford University Press, 1977.

YERBA MALA CARTONERA. <https://yerbamalacartonera.blogspot.com/> Fecha de captura: 20.12.2018.

YVONNE CARTONERA. <http://yvonnecartonera.blogspot.fr/>. Fecha de captura: 20.12.2018. 
Analía Isabel Gerbaudo. Doctora en Letras Modernas. Investigadora Independiente del CONICET. Profesora Titular de Teoría Literaria I y de Didácticas de la lengua y de la literatura en la Universidad Nacional del Litoral. Directora del Programa de Investigación La lengua, la literatura y otros bienes culturales en la escena internacional de circulación de las ideas. Directora de la revista El taco en la brea y de la editorial Vera cartonera.

E-mail: analiagerbaudo71@yahoo.com.ar 